\title{
PENINGKATAN EFISIENSI DAN PRODUKTIVITAS HASIL PANEN AYAM BROILER UNTUK POTENSI DESA MELALUI ANALISIS SWOT AGAR TERCIPTANYA UMKM YANG UNGGUL
}

\author{
Amir 1 \\ Universitas Buana Perjuangan Karawang \\ Program Teknik Mesin, Fakultas Teknik dan Ilmu Kmputer \\ amir@ubpkarawang.ac.id
}

\begin{abstract}
Abstrak
Desa Sampalan merupakan salah satu desa yang ada di Kecamatan Kutawaluya, Kabupaten Karawang, Provinsi Jawa barat, Indonesia. UMKM merupakan salah satu tonggak perekonomian masyarakat setempat. Meskipun pada kenyataannya sebagian besar usaha UMKM masih berjalan ala kadarnya dan masih skala kecil, namun tidak dapat dipungkiri jika sektor UMKM ini sangat berperan bagi perekonomian masyarakat setempat. Peternakan ayam broiler atau ayam potong, di desa Sampalan sendiri terbilang cukup besar dan juga hasil panen dari peternakan ayam broiler ini menjadi salah satu pemasok kebutuhan daging ayam Kabupaten Karawang sehingga bias memasok ayam ke DKI Jakarta dan Jawa Barat khususnya. Permintaan yang cukup besar menjadikan peternakan ayam broiler di desa Sampalan ini terus berkembang. Namun peternakan ayam yang sudah ada ini belum dapat maksimal mensejahterakan masyarakat yang ada di desa Sampalan. Sumber daya yang ada saat ini yang menjadi potensi ekonomi yang unggul adalah di bidang pertanian dan dengan beberapa produk yang dihasilkan, meliputi: Padi, peternakan kambing, bebek, ayam broiler, telur asin dan yang lainnya. Berdasarkan situasi dan kondisi data desa diatas maka dengan Penelitian ini bertujuan untuk mengidentifikasi potensi dan kendala yang dimiliki desa dengan anaslisis SWOT. Analisis SWOT bertujuan untuk mengetahui kekuatan dan kelemahan serta kesmpatan dan ancaman yang dimiliki desa. Hasil dari penelitian ini menunjukkan rendahnya tingkat ekonomi pada masyarakat yang diakibatkan kurangnya pengelolaan hasil pertenakanayam boiler atau ayam potong.
\end{abstract}

\footnotetext{
Abstrack

Sampalan Village is one of the villages in Kutawaluya District, Karawang Regency, West Java Province, Indonesia. UMKM is one of the pillars of the local community's economy. Even though in fact most of the MSME businesses are still running perfunctorily and are still on a small scale, it cannot be denied that the MSME sector plays a very important role in the economy of the local community. The broiler chicken farm or broiler chicken, in Sampalan village itself is quite large and also the yield from the broiler chicken farm is one of the suppliers of
} 
chicken meat needs in Karawang Regency so that it can supply chicken to DKI Jakarta and West Java in particular. The demand is large enough to make the broiler chicken farm in Sampalan village continue to grow. However, the existing chicken farm has not been able to maximize the welfare of the people in Sampalan village. The current resources that have a superior economic potential are in the field of agriculture and with several products produced, including: Rice, goat, duck, broiler chickens, salted eggs and others. Based on the situation and condition of the village data above, this study aims to identify the potential and constraints that the village has with a SWOT analysis. The SWOT analysis aims to determine the strengths and weaknesses as well as the opportunities and threats that the village has. The results of this study indicate the low level of the economy in the community due to a lack of management of boiler or broiler farming.

Keywords : analysis SWOT, welfare of community, human resources

\section{PENDAHULUAN}

Pendampingan masyarakat
dapat definisikan sebagai suatu
bentuk hubungan antara kelompok
masyarakat dan pendamping yang
bertujuan menghadapi tantangan dalam berbagai aspek seperti: Ekonomi masyarakat sarana dan prasarana, kesehatan, tingkat pendidikan masyarakat, sosial dan budaya (Qmariah, 2016). Peran yang dimiliki pendampingan sosial sangat menentukan keberhasilan program pemberdayaanzmasyarakat. dalam mencapai tujuannya dalam hal pembangunan desa secara berkesinambungan. Desa Sampalan merupakan salah satu desa yang ada di Kecamatan Kutawaluya, Kabupaten Karawang, Provinsi Jawa barat, Indonesia. Desa Sampalan memiliki luas wilayah 362.6 Hektar, terdapat 6.355 orang jumlah penduduk dan 1.963 KK. Di desa Sampalan sendiri, UMKM merupakan salah satu tonggak perekonomian masyarakat setempat. Meskipun pada kenyataannya sebagian besar usaha UMKM masih berjalan ala kadarnya dan masih skala kecil, namun tidak dapat dipungkiri jika sektor UMKM ini sangat berperan bagi perekonomian masyarakat setempat. Usaha Kecil Mikro Menengah (UMKM) memilik peran strategis dalam pembangunan ekonomi di Indonesia. Tidak hanya berperan dalam penyerapan tenaga kerja dan pengentasan kemiskinan, UMKM juga terbukti mampu bertahan dan menjalankan perannya dengan baik ditengah terjadinya krisis multidimensi. Hal ini cukup 
beralasan mengingat sektor usaha kecil menengah memiliki prospek yang lebih tinggi untuk dikembangkang. Salah satu UMKM yang ada di desa Sampalan yaitu Peternakan ayam broiler.

\section{METODE}

\section{Program Kegiatan}

Kegiatan ini di fokuskan pada identifikasi permasalah yang terjadi dilingkungan masyarakat desa Sampalan kemudian lakukan analisis dan menemukan solusi atas permasalahan yang ada.

\section{Analisa Kebutuhan Program}

Dalam kegiatan ini dibutuhkan data-data yang terkait dengan desa khususnya tentang permasalahan peternak ayam boiler.

\section{Model atau Pendekatan}

Untuk memperoleh data pada penelitian ini dilakukan pendekatan secara langsung melalui wawancara dengan responden langsung terkait permasalahan yang ada tentang peternak ayam boiler desa Sampalan

\section{Peserta yang Terlibat}

Peserta yang terlibat pada pengabdian masyarakat ini terdiri dari Dosen pembimbing lapangan (DPL), Mahasiswa dan responden peternak ayam boiler.

\section{Penyelesaian Masalah}

Penyelesaian maslah dilakukan dengan cara mengidentifikasi permasalahan yang ada didesa Sampalan dengan analisis SWOT.

Tujuannya untuk mengetahui kelebihan dan kekurangan, serta peluang dan acaman yang terdapat didesa tersebut.

\section{Hasil yang diharapkan}

Hasil yang diharapkan dengan adanya kegiatan pengabdian masyarakat ini adalah dapat membantu dalam mengembangkan potensi desa dalam beternak ayam boiler dan terciptanya tujuan pembangunan berkelanjutan.

\section{HASIL DAN PEMBAHASAN}

Analisis SWOT digunakan untuk mencari solusi yang tepat bagi permasalahan yang ada. Strategi dan solusi atas permasalahan yang mengacu pada kelemahan dan 
ancaman Desa Sampalan yang kesempatan yang ada tersebut disesuaikan dengan kekuatan dan dirumuskan sebagai berikut ini:

Tabel 1 Matrik SWOT

\begin{tabular}{|c|c|c|}
\hline Matrik SWOT & $\begin{array}{l}\text { Peluang-Opportunity }(O) \\
\text { - Peternak umumnya } \\
\text { usaha bekerja sambil } \\
\text { usaha tani. } \\
\text { - Peternak melakukan } \\
\text { usaha penjualan ayam } \\
\text { potong ke Bandar atau } \\
\text { agen ayam potong. }\end{array}$ & $\begin{array}{l}\text { Ancaman-Threat }(T) \\
\text { - Persaingan hasil } \\
\text { perternakan dari desa } \\
\text { lain. } \\
\text { - Seringnya terjadi } \\
\text { kematian pada ayam } \\
\text { ternak, pencurian } \\
\text { barang ternak. }\end{array}$ \\
\hline $\begin{array}{l}\text { Kekuatan-Strength }(S) \\
\text { - Terdapat sarana umum } \\
\text { Terdapat sarana dan } \\
\text { fasilitas Sumber daya } \\
\text { alam memadai dalam } \\
\text { segi luas wilayah dan } \\
\text { kesuburan tanahyang } \\
\text { masih kosong }\end{array}$ & $\begin{array}{l}\text { (S 1,2- O 1,2) } \\
\text { Pemerintah daerah } \\
\text { setempat mengadakan } \\
\text { pelatihan untuk } \\
\text { meningkatkan skill SDM } \\
\text { terkait teknologi dan } \\
\text { informasi pengolahan } \\
\text { sumber daya tentang } \\
\text { ternak ayam boiler. }\end{array}$ & 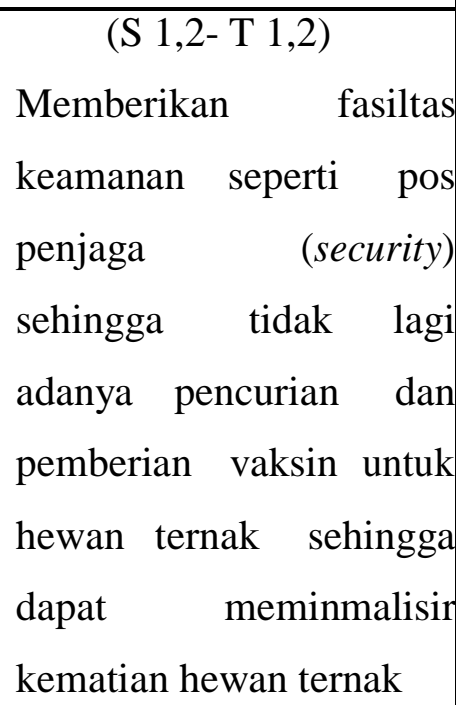 \\
\hline $\begin{array}{l}\text { Kelemahan-Weakness } \\
(w) \\
\text { - Skill SDM yang masih } \\
\text { rendah tentang } \\
\text { pengelolaan ternak } \\
\text { ayam } \\
\text { - Masih terkendalanya } \\
\text { jaringan penjualan hasil } \\
\text { ternak ayam boiler }\end{array}$ & $\begin{array}{l}\quad \text { (W 1,2- O 1,2) } \\
\text { - Pengembangan SDM } \\
\text { informasi pengelolaan } \\
\text { ternak ayam boiler } \\
\text { - Pengembangan } \\
\text { jaringan untuk } \\
\text { penyaluran hasil ternak }\end{array}$ & $\begin{array}{l}\text { (W 1,2- T 1) } \\
\text { - Melakukan pelatihan } \\
\text { tentang tata cara } \\
\text { pengelolaan ternak } \\
\text { ayam boiler dan } \\
\text { strategi pemasaran } \\
\text { hasil ternak tersebut. }\end{array}$ \\
\hline
\end{tabular}


\begin{tabular}{|l|l|l|}
\hline- & \\
\hline
\end{tabular}

Sumber: Pengolahan data, 2020

\section{Pengembangan Potensi Desa}

Banyaknya area persawahan
di desa Sampalan memberikan
potensi yang baik untuk area
peternakan ayam broiler, karena kendang membutuhkan area yang memiliki sirkulasi angin terbuka seperti di area persawahan. Potensi yang baik ini dapat dimanfaatkan untuk membuat peternakan ayam broiler, masyarakat desa sampalan perlu menambah tempat peternakan ayam broiler karena banyak potensi yang didapatkan dari hasil panen ayam ini dapat dibuat olahan lain yang dapat memunculkan UMKM olahan ayam lainnya. Sehingga lebih banyak UMKM tercipta dapat lebih cepat mengembangkan perekonomian desa Sampalan.

\section{KESIMPULAN DAN SARAN}

\section{Kesimpulan}

Berdasarkan kegiatan yang telah dilakukan dapat disimpulkan yaitu sebagai berikut:

1. Desa Sampalan memiliki luas wilayah 362.6 Hektar dan sebagian besar mata pencaharian warga setempat yaitu petani dan beternak ayam boiler

2. Kurangnya pelatihan mengenai cara beternak ayam boiler yang baik dan benar dari dinas terkait pengelolaan hasil pertanian dan hasil ternak ayam boilr padahal luas wilayah persawahan cukup luas jika bisa dimanfaatkan dengan baik dapat membantu perekonomian masyarakat

3. Kurangnya keamanan sehingga masih banyak kasus pencurian

4. Tujuan pembangunan berkelanjutan ini harus diperhatikan agar terciptanya Desa yang makmur dan sejahtera

\section{Saran}

Adanya pandemi mengakibatkan sulitnya melakukan kegiatan pengabdian kepada masyarakat, sehingga rencana mengembangkan potensi Desa tidak dapat berjalan semestinya. Semoga kegiatan berikutnya dapat dilakukan secara langsung agar dapat membantu dalam mengembangkan 
potensi desa dan agar terciptanya

tujuan pembangunan berkelanjutan.

\section{DAFTAR PUSTAKA}

Lembaga Penelitian dan Pengabdian kapada Masyarakat. 2020. Buku Panduan Kuliah Kerja Nyata Online Tahun 2020. Universitas Buana Perjuangan. Karawang.

Muh. Rudi Nugroho (2018) Journal Penerapan Pola Sinergitas

Antara BUMDES dan

UMKM dalam Menggerakkan

Desa Di Kecamatan Saptosari.
Qomariah, N. 2016. Pemberdaya-an Masyarakat Desa Melalui Pengembangan " Soft Skill Pembuatan Krupuk Samiler" dalam Upaya Peningkatan Pendapatan Keluarga di Kabupaten Bondowoso. Jurnal Pengabdian Masyarakat IPTEKS. Jawa Timur 